\title{
PENGELOLAAN LIMBAH ORGANIK MENJADI KOMPOS MELALUI PEMBUATAN TONG SUPER
}

\author{
Imam Sundarta ${ }^{1}$, Atika Yunda Sari, Hendra Prasetyo Wibowo ${ }^{2}$ \\ imam@uika-bogor.com \\ Dosen Fakultas Ekonomi ${ }^{1}$, Mahasiswa KKN Kelompok 42 Tahun $2018^{2}$
}

\begin{abstract}
ABSTRAK
Produksi sampah domestik sangat besar dan menjadi masalah global yang belum terpecahkan sampai saat ini. Sampah merupakan bagian dari kehidupan manusia. Sampah adalah benda/zat sisa yang sudah tidak terpakai. Seharusnya sampah mendapat perhatian dan penanganan yang serius. Namun karena kurangnya pengertian masyarakat dan pemerintah, juga kurangnya biaya dan pendapatan sebagian besar masyarakat, maka masalah sampah ini menjadi terabaikan. Saat ini sebagian besar masyarakat telah mengetahui dampak buruk sampah, antara lain menyebabkan banjir, penyakit dan bau yang dapat mengganggu kehidupan, tapi hal ini tidak diimbangi oleh perilaku masyarakatnya sendiri. Tong super menjadi salah satu cara untuk mengurangi dampak buruk sampah dengan mengelola limbah organik menjadi kompos, sehingga nantinya dapat di manfaatkan oleh warga untuk bercocok tanam.
\end{abstract}

Kata kunci: Sampah, Pengelolaan, Tong super.

\section{PENDAHULUAN}

\section{Latar Belakang}

Salah satu fakor yang menyebabkan kerusakan lingkungan hidup sampai saat ini masih tetap menjadi sebuah masalah terbesar bagi bangsa indonesia adalah pembuangan sampah. Sampah-sampah itu diangkat oleh truk-truk khusus kemudian dibuang dan ditumpuk begitu saja di tempat yang sudah di sediakan tanpa adanya pengolahan bagi sampah tersebut. Hal tersebut sangatlah berpengaruh kepada lingkungan sekitar, di mana lingkungan menjadi kotor dan dapat membawa dampak buruk pada kesehatan, karena sampah yang berserakan dan membusuk akan di datangi oleh serangga-serangga yang nantinya akan menimbulkan bibit penyakit.
Sampah merupakan sisa material yang tidak di inginkan dari berakhir sebuah proses. Pertambahan jumlah penduduk, perubahan pola konsumsi dan gaya hidup masyarakat telah meningkatkan jumlah timbulnya jenis dan karakteristik sampah. Meningkatnya daya beli masyarakat terhadap berbagai jenis bahan pokok dan hasil teknologi serta meningkatnya usaha atau kegiatan yang menunjang pertumbuhan ekonomi suatu daerah juga memberikan kontribusi yang besar terhadap kuantitas dan kualitas sampah yang di hasilkan.

Walaupun terbukti sampah itu dapat merugikan bila tidak di kelola dengan baik, tetapi ada sisi manfaatnya hal ini karena selain dapat mendatangkan bencana bagi masyarakat, sampah juga dapat di ubah menjadi sebuah barang atau produk yang mempunyai nilai tinggi. Kemanfaatan 
sampah ini tidak terlepas dari penggunaan ilmu pengetahuan dan teknologi dalam menanganinya dan juga kesadaran dari masyarakat untuk pengelolaan sampah. Jadi agar sampah ini tidak meenimbulkan bibit penyakit perlu di kelola dengan dan perlu dilakukan pemilahan agar dapat di manfaatkan dengan benar.

Jenis sampah dapat dibagi berdasarkan sifatnya. Sampah dipilah menjadi sampah organik dan sampah anorganik. Sampah organik atau sampah basah ialah sampah yang berasal dari makhluk hidup, seperti dedaunan, sisa makanan dan sampah dapur. Sampah jenis ini sangat mudah terurai secara alami (degradable). Sedangkan sampah anorganik adalah sampah yang tidak dapat terurai (undegradable), seperti karet, plastik, kaleng dan logam.

Sampah organik dapat di manfaatkan dan dapat di olah menjadi pupuk kompos cair dan padat. Kompos adalah pupuk organik yang terurai secara lambat dan merangsang kehidupan tanah serta memperbaiki struktur tanah. Kompos sebagai salah satu contoh pupuk organik, sangat baik dan bermanfaat untuk segala jenis tanaman, $m$ ulai dari tanaman hias, tanaman sayuran, tanaman buah-buahan sampai ke tanaman pangan dan perkebunan.

\section{Potensi Sumber Daya dan Bahan Baku}

Desa Cimayang kecamatan Pamijahan Kabupaten Bogor memiliki kurangnya fasilitas tempat pembuangan sampah yang memadai di setiap RT dan RW kita melihat sampah yang berserakan maka dari itu kami pun langsung sigap untuk menangani masalah sampah ini karena sampah yang timbulkan hanya berasal dari limbah rumah tangga dan limbah pasar cimayang maka dari itu kita manfaatkan dari sampah organik.

\section{Peluang Pasar}

Melihat situasi diwilayah tersebut sasaran untuk program kerja ini sangatlah strategis maka munculnya daya inovasi dan kreatifitas dalam bidang kesehatan dapat menjadi peluang melakukan suatu kegiatan pengolahan limbah organik, tong super memiliki potensi nilai yang tinggi karena masyarakat pun banyak yang mengeluhkan tidak adanya pengolahan sampah dari pihak desa. Dengan ini kami harap bisa memajukan desa tersebut dan merubah pola fikir masyarakat terhap sampah yang bisa di kelola dengan baik.

\section{METODOLOGI}

\section{Tahap awal pembuatan Tong Super}

1. Memanfaatkan tong bekas ember cat atau tong yang tidak terpakai dan pipa ukuran 1/5 inch dan 1.1/5 inch

2. Potong pipa ukuran $1 / 5$ inch menjadi 5 bagian yang nantinya akan di pasang pada pipa ukuran 1.1/5 inch dan kemudian lubangi ember cat dengan ukuran yang sama pada pipa 1/5 inch dengan bor

3. Kemudian lubangi ember cat dengan ukuran yang sama pada pipa 1/5 inch dengan bor

4. Setelah di lubangi pasang pipa tersebut pada ember/tong yang sudah di lubangi

5. Jika sudah pasang polycarbonate pada bagian dalam ember/tong dan pasang selang untuk mengalirkan hasil dari pembusukan sampah

6. Siapkan cairan EM4, air cucian beras dan air gula merah bahan tersebut adalah untuk pembuatan bioaktifator yang nantinya bioaktifaor berfungsi untuk mempercepat proses pembusukan 
pada sampah organik yang berada di dalam tong super tersebut.

\section{Tahap akhir}

Masukkan sampah organik pada tong super kemudian semprotkan cairan bioaktifator pada sampah organik tersebut dan jika sudah di semprotkan tunggu hingga 1 bulan maka akan jadilah pupuk kompos padat dan cair

\section{ANGGARAN TONG SUPER}

\begin{tabular}{|l|l|}
\hline Tong & Rp. 100.000 \\
\hline Pipa $1 / 5$ inch & Rp. 18.000 \\
\hline Pipa $1.1 / 5$ inch & Rp. 22.000 \\
\hline polycarbonate & Rp. 20.000 \\
\hline EM 4 & Rp. 20.000 \\
\hline & \\
TOTAL & Rp. 180.000 \\
\hline
\end{tabular}

\section{REALISASI KEGIATAN}

Kegiatan penyuluhan tong super dari sampah organik dilaksanakan pada hari Rabu tanggal 31 Agustus 2018 bertempat di aula RT 10 RW 04 Kp. Cimayang dukuh Ds. Cimayang Kec. Pamijahan Kab. Bogor. Selama sekitar dua jam dari Jam $15.00 \mathrm{~s} / \mathrm{d} 17.00$.
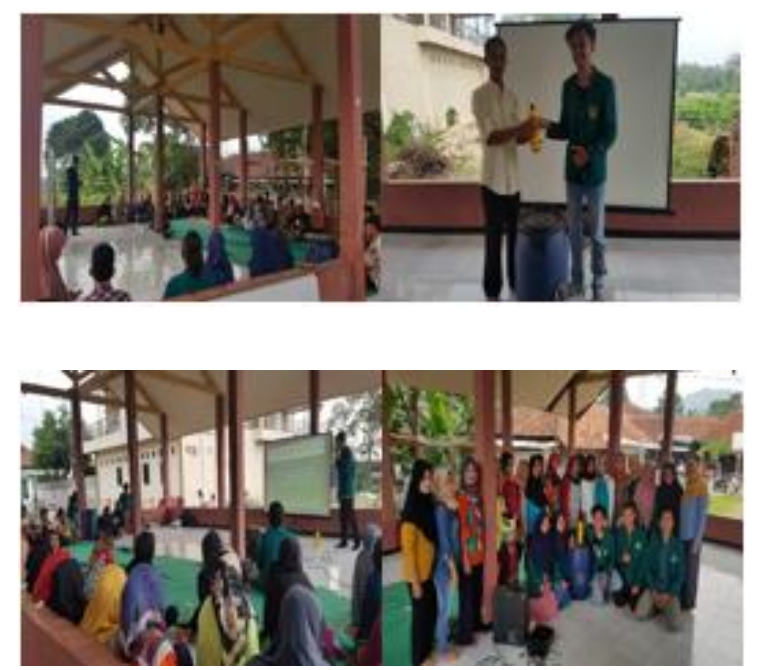

\section{KESIMPULAN}

1. Menciptakan pengolahan sampah organik yang nantinya bisa di manfaatkan warga untuk bercocok tanam

2. Mengedukasi masyarakat bahwa pentingnya pengolahan sampah organik

\section{REFERENSI}

Nurjazuli, Asti Awiyatul, Cut Juliana. (2016). Teknologi Pengolahan Sampah Organik Menjadi Kompos Cai. Padang: Seminar Nasional Sains dan Teknologi Lingkungan II.

Rahmat Rosadi, Eska Perdana Prasetya. (2018). Pelaksanaan KKN Tematik Terintegritas . Bogor: Uika Press.

Siratul Hati. (2018). Pembuatan Pupuk Kompos Cair Dari Limbah Rumah Tangga Sebagai Penunjang Mata Kuliah Ekologi dan Masalah Lingkungan. Aceh

Unus, Suriawiria. (2002). Pupuk Organik Kompos dari Sampah, Bioteknologi Agroindustri. Bandung : Humaniora Utama Press. 